\title{
Recognition Memory for Faces and Scenes
}

\author{
$\operatorname{AUTHOR}(\mathrm{S})$ :
}

Sato, Wataru; Yoshikawa, Sakiko

CITATION:

Sato, Wataru ...[et al]. Recognition Memory for Faces and Scenes. The Journal of General Psychology 2013, 140(1): 1-15

ISSUE DATE:

2013-01

URL:

http://hdl.handle.net/2433/182054

\section{RIGHT:}

(c) 2013 Taylor \& Francis Group, LLC; この論文は出版社版でありません 。引用の際には出版社版をご確認ご利用ください。; This is not the published version. Please cite only the published version. 


\title{
Recognition Memory for Faces and Scenes
}

\author{
Wataru Sato and Sakiko Yoshikawa (Kyoto University)
}

\begin{abstract}
Author Note
This study was supported by funds from the Benesse Corporation and JSPS Funding Program for Next Generation World-Leading Researchers.

Correspondence should be directed to: Wataru Sato, The Hakubi Project, Primate Research Institute, Kyoto University, Inuyama, Aichi 484-8506, Japan (E-mail: sato@pri.kyoto-u.ac.jp).

Abstract

Previous studies have suggested that face memory is unique; however, evidence is inconclusive. To further explore this issue, we investigated recognition memory for unfamiliar faces and scenes. Participants $(n=123)$ intentionally memorized the stimuli and then engaged in recognition tests. Recognition was measured following short (20 minutes) and long (3 weeks) retention intervals. Encoding strategies and intelligence were also measured. Recognition memory performance for faces was higher than that for scenes at both short- and long-intervals; however, the effect of retention interval was different between faces and scenes. A relationship between encoding strategies and memory performance was found for scenes but not for faces. The relationship between intelligence and memory performance also differed between faces and scenes. These results suggest that memory for faces is more robust and uses different cognitive mechanisms than does memory for scenes.
\end{abstract}

Keywords: Recognition memory; face; scene; retention interval; intelligence.

\section{Introduction}

Memorizing faces is a ubiquitous and essential cognitive skill in daily life. Based on the astonishing human ability to recognize a large number of faces, several researchers have long posited that faces act as special stimuli (cf. Elgar \& Campbell, 2001). Previous psychological and neuroscientific research has suggested that memory for faces is unique compared with memories for other types of objects (for a review, see Robbins \& McKone, 2007). For instance, a previous study tested the recognition memory for faces and other objects (e.g., houses, airplanes) presented in upright and inverted positions (Yin, 1969). The results showed that the superiority of memory for faces compared with that for objects was greater for the upright than for the inverted position. A neuropsychological case study reported that recognition memory was impaired for faces but not for objects in a brain-damaged patient (McNeil \& Warrington, 1993). These findings suggest that memory for faces is special in terms of cognitive processing and neural hardware. 
However, the uniqueness of face memory has not been conclusively demonstrated. Ongoing debate over whether facial processing truly differs from processing of other types of stimuli persists (e.g., Gauthier, Williams, Tarr, \& Tanaka, 1988; Robbins \& McKone, 2007) as does the question of whether a neural substrate specific to processing faces exists (e.g., Gauthier, Skudlarski, Gore, \& Anderson, 2000; Grill-Spector, Knouf, \& Kanwisher, 2004). Therefore, further evidence for the specificity of facial memory is needed.

The purpose of the present study was to investigate the uniqueness of facial recognition memory. To accomplish this purpose, we first compared memory for faces with that for scenes. Both faces and scenes are non-linguistic, complex, and ecologically valid stimuli. Previous psychological research has shown that visual processing patterns differ between face and scene recognition (Diamond \& Carey, 1986). Also, neuroscientific findings suggest that the neural correlates of two types of memory are independent. For example, one study revealed dissociation between memory for faces and that for scenes (Taylor, Henson \& Graham, 2007). A neuroimaging study also indicated that distinctive brain areas were activated in face versus scene processing (Nakamura et al., 2000). However, little psychological research directly compares recognition memory for faces and scenes.

Second, we investigated the influence of retention interval. Previous work has shown that a difference in retention intervals produces qualitative differences in facial memory representation (Yoshikawa, 1995). In that study, facial memory recognition was examined at a short retention interval (10 minutes) and a long retention interval (1 week) and compared with participants' self-assessments of their memory for faces in their daily lives. The results showed a positive correlation between self-assessment and performance at the long-interval but not at the short-interval. Supporting these dissociations, recognition memory for faces is impaired in patients with idiopathic generalized epilepsy (with damage in the frontal and parietal areas) only at short retention intervals, whereas impairment appears in patients with temporal epilepsy (with damage in the medial temporal lobe) only at long retention intervals (Bengner et al., 2006; Hötting, Katz-Biletzky, Malina, Lindenau, $\&$ Bengner, 2010). These data suggest that the recognition memory for faces at different retention intervals is related to dissociable neural underpinnings. In sum, these findings suggest that recognition memory may use qualitatively different cognitive mechanisms depending on retention interval.

Third, we tested the influence of encoding strategies on memory performance. Encoding strategy is the type of information processing used when participants memorize experimental stimuli. Encoding strategy effects have long been examined in empirical studies of verbal memory, and the effectiveness of categorical organization and imaging strategies has been confirmed (e.g., Craik \& Lockhart, 1972). In contrast, debate about the effect of encoding strategies on face memory continues (cf. Coin \& Tiberghien, 1997). Whereas some previous studies have reported that encoding strategies have no effect on recognition memory for faces (e.g., Woodhead, Baddeley, \& 
Simmonds, 1979; Malpass, 1981), other studies have found a positive influence of encoding strategy (e.g., Bower \& Karlin, 1974; Parkin \& Goodwin, 1983). Clarifying this issue would be informative in understanding the cognitive mechanisms of facial memory.

Fourth, we explored the relationship between intelligence and memory performance. Intelligence refers to a comprehensive cognitive function and can be divided into two types based on the contents of information processing: visuospatial and verbal intelligence. Regarding the relationship between intelligence and recognition memory, some studies on verbal information report a positive correlation. For example, Coyle's (2001) study indicated a positive correlation between children's verbal intelligence and their recognition memory for verbal stimuli. However, no consensus about the overall relationship between intelligence and facial recognition memory has emerged. The majority of research has found no significant relationship (Bowles et al., 209; Dobson \& Rust, 1994; Feiman \& Entwisle, 1976; Howells, 1938; Kaess \& Witryol, 1955; McCartney, 1987; Wojcikiewicz, 1990; however, see Diesfeldt \& Vink, 1989; Herlitz \& Yonker, 2002). However, most previous studies did not differentiate between visuospatial and verbal intelligence and did not test multiple retention intervals. Therefore, it may be possible to identify relationships between intelligence and memory performance when considering these variables.

In summary, to investigate the uniqueness of memory for faces, we compared it to scene memory. We also tested the influence of retention interval on memory performance, comparing two different retention intervals (short: 20 minutes; long: 3 weeks). Finally, we examined the relationships of encoding strategies and intelligence with memory performance. Because some previous data indicated superior memory performance for faces versus non-face stimuli (e.g., Yin, 1969), we predicted that recognition memory for faces would be more robust than that for scenes. Furthermore, based on the aforementioned findings suggesting differences in the cognitive/neural mechanisms for faces and scenes (e.g., Diamond \& Carey, 1986), we expected that the effect of retention interval might differ between facial and scene memory. We also expected that different relationships of encoding strategies or intelligence with memory performance might be observed between faces and scenes and between retention intervals.

\section{Method}

\section{Participants}

One hundred twenty-three undergraduates ( 80 females and 43 males; mean age 20.8 years) participated in this experiment.

\section{Stimuli}

The faces were color pictures of 40 adult males. All pictures were taken from the chin level up to exclude the influence of clothing. Twenty pictures were randomly selected and used as memorization targets, and the other 20 pictures were used as distractors during the recognition tests. 
The scenes were color pictures of 40 natural settings. Appropriate pictures (e.g., seashores) were collected, and the pictures that did not include particular objects or buildings were selected for the stimuli. Twenty pictures were randomly selected and used as memorization targets, and 20 pictures were used as distractors during the recognition tests.

Procedure

The experiment took place in a classroom that could hold about 80 students. From 10 to 30 participants were tested at once. At the beginning of the experiment, participants were told that our purpose was to investigate intentional memory for faces and scenes, and they were informed about the retention intervals.

Memorization. The pictures were projected on a large screen by a carrousel slide projector with a shutter. The screen hung from the ceiling, and the pictures were presented one by one. The presentation time was set at 2 seconds and controlled by a pre-set timer, an electronic shutter, and a shutter driver. The picture was $100 \mathrm{~cm}$ in height and $70 \mathrm{~cm}$ in width. The distance from the screen to participants in the front row was about $2.8 \mathrm{~m}$, and the distance to the back row was about $11.5 \mathrm{~m}$. Prior to the experiment, a sample slide was presented, and participants who had difficulty seeing the picture were instructed to change their seats. Our preliminary experiment confirmed that participants with normal visual acuity could clearly observe the stimuli in the current setting. A previous study had also suggested that recognition of unfamiliar faces of actual size (much smaller than the current condition) would be optimal if the distance were less than $15 \mathrm{~m}$ (Wagenaar \& van der Schrier, 1996).

Forty pictures (20 faces and 20 scenes) were presented in two separate blocks of 20 pictures. Each block contained each stimulus type (faces or scenes). The order of blocks was counterbalanced across participants, and the order of pictures was randomized in each block.

Strategy evaluation. After the memorization session, participants were asked to rate their use of the following four encoding strategies for each stimulus type: (1) "How often did you try to notice distinctive features of stimuli to remember them?" (feature strategy); (2) "How often did you try to form an overall visual impression of stimuli to remember them?" (configuration strategy); (3) "How often did you try to recall similar faces or scenes to remember stimuli?" (similarity strategy); and (4) "How often did to you try to form a preference for stimuli to remember them?" (preference strategy). Ratings were made on 5-point scales ranging from "not at all" (1) to "very often" (5). These strategies were drawn from previous research (e.g., Bower \& Karlin, 1974), and we confirmed participants' reported use of these strategies for intentional facial memory tasks (Yoshikawa, 1995).

Intelligence evaluation. After finishing the strategy evaluation, participants engaged in six tasks (three to measure visuospatial intelligence and three to measure verbal intelligence) drawn from the Kyoto University NX 15 Intelligence Test (Taisei Shuppan, Tokyo, Japan). This is a paper-and-pencil intelligence test that has been standardized (Osaka \& Umemoto, 1973) and widely used (Sato, Namiki, Ando, \& Hatano, 2004) in Japan. Subtests of this test have been shown to provide 
information on intelligence types, including visuospatial and verbal intelligence (Osaka \& Umemoto, 1973). After completion of the task, participants waited for the next instruction.

Short-interval recognition. Twenty minutes after the end of the memorization session, the recognition session for the short retention interval was conducted. Twenty previously memorized pictures (i.e., half the stimuli presented in the memorization session: 10 faces and 10 scenes) and 20 distractors (10 faces and 10 scenes) were presented. As in the case of the memorization session, the pictures of faces and scenes were presented in two separate blocks. The block order was counterbalanced across participants and the picture order was randomized in each block. The participants were asked to recognize pictures by choosing "seen" for pictures that they had seen in the memorization session and "not seen" for pictures they had not seen.

Long-interval recognition. Three weeks later, the long-interval recognition session was conducted. Twenty previously memorized pictures (10 faces and 10 scenes) and 20 distractors (10 faces and 10 scenes), none of which had been used for the short-interval session, were presented at this time. The procedures for picture presentation and recognition ratings were identical to those used in the short-interval recognition session.

\section{Data analysis}

Using memory performance as an index, we calculated d' based on the hit rate and false alarm rate for each condition (short- versus long-interval and face versus scene recognition). For encoding strategies, we analyzed the participants' self-ratings. For intelligence, we calculated a score for each task. For verbal intelligence task 3 , a positive skewness was observed, so the data were analyzed after logarithmic transformation (the skewness was corrected from 3.70 to .06 ).

The recognition memory performance data were initially analyzed using one-sample t-tests (two-tailed) to test for differences from zero. Then, the data were analyzed using analysis of variance (ANOVA) with stimulus type (face versus scene) and retention interval (short versus long) as within-participant factors.

To examine associations of encoding strategies and intelligence with recognition memory, we conducted structural equation modeling (SEM) using the models shown in Figure 2. The SEM was implemented using Amos 4.01 (SmallWaters, Chicago, IL). Maximum likelihood estimation was used for the model estimation. We manipulated the paths from the four strategies (feature, configuration, similarity, preference) to recognition memory performance (Figure 2 left, marked as A) and the paths from the two types of intelligence (visuospatial, verbal) to recognition memory performance (Figure 2 right, indicated as B). Memory performance at short- and long-intervals was analyzed for faces and scenes. To evaluate the fit of the model, we computed $\chi^{2}$, the adjusted goodness of fit index (AGFI), and root mean square error of approximation (RMSEA). To compare models, the Akaike information criterion (AIC) was computed.

In a preliminary analysis, we conducted an ANOVA with sex as an additional factor and found 
no significant main effects or interactions related to this factor. We also conducted SEM separately for males and females and found that the path coefficients did not show sign reverses or changes in significance. Therefore, we report results collapsed across sexes.

\section{Results}

\section{Recognition memory performance}

For recognition memory performance (Figure 1), we initially performed one-sample t-tests to test for differences from the chance level (i.e., zero). All conditions differed significantly from zero (ts $(122)>15.54, \mathrm{ps}<.001)$. The results indicate that the memory performance for both faces and scenes was well above chance even after the long-interval.

The two-way ANOVA for recognition memory performance revealed that all main effects of stimulus type and retention interval, as well as the interaction of stimulus type with retention interval, were significant $(\mathrm{F}(1,122)=116.33,91.51$, and 40.35, respectively; ps $<.001)$. Recognition memory performance was better for faces than for scenes. It was also better with a short-interval than with a long-interval. Simple effect analyses for the interaction showed that recognition memory performance for faces was better than that for scenes at both short- and long-intervals $(F(1,244)=$ 149.49 and 12.86 , respectively, ps $<.001)$. However, it must be noted that the significant interaction of stimulus type $\times$ retention interval indicated that the effect of retention interval was different across stimulus types.

\section{Relationships between encoding strategies and recognition memory}

Using Model A from Figure 2, we investigated the relationship between encoding strategies and memory performance (Table 1). For all data except for scene memory at a long-interval, models with no path were selected as optimal. For the scene memory at a long-interval, a model in which the configuration strategy had a positive influence on memory was selected as optimal. The fitness indices of these models were highly acceptable.

\section{Relationship between intelligence and recognition memory}

To confirm the validity of the assumed structures of intelligence, an exploratory factor analysis was first performed. The principal factor analysis with promax rotations confirmed two main factors (explaining $60.7 \%$ of the total variance). The factor pattern matrix indicated that the three verbal tasks composed one factor, and the three visuospatial tasks composed the other.

Using Model B in Figure 2, we examined the relationship between intelligence and memory performance (Table 2). For face recognition memory a a short-interval, the model in which verbal intelligence had a positive influence on recognition memory was optimal. For facial memory at a long-interval, the model in which verbal intelligence had a negative influence on memory was 


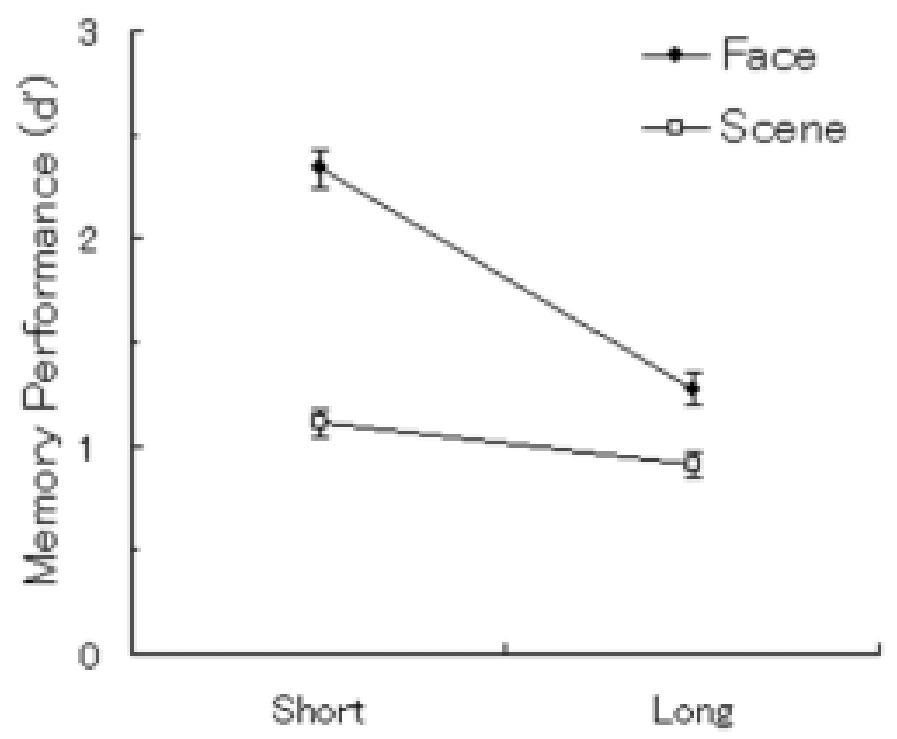

Retention Interval

Figure 1. Mean $( \pm \mathrm{SE})$ recognition memory performance.

A

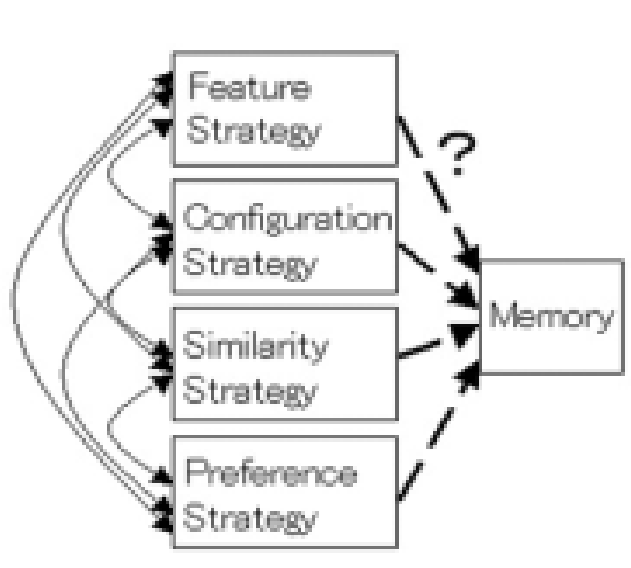

B

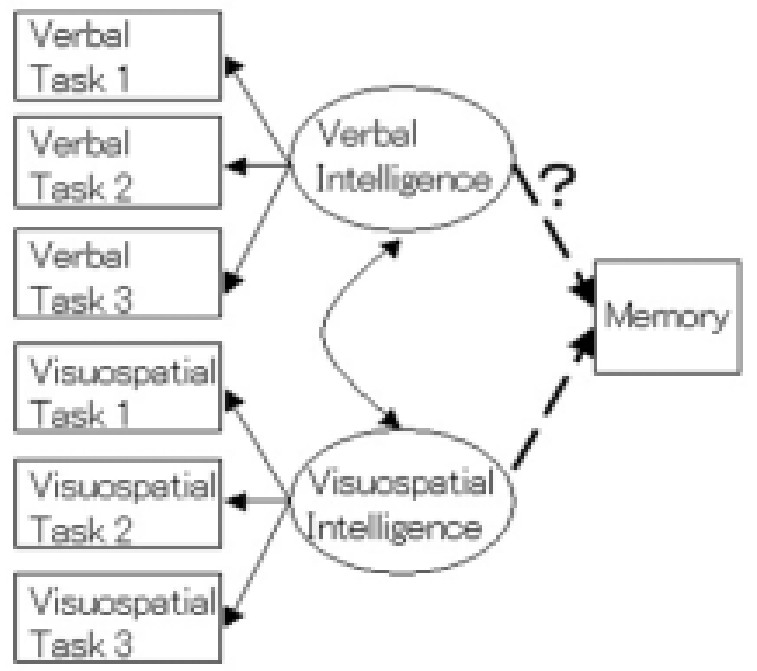

Figure 2. The theoretical models used for the structural equation modeling analyses. (A) The model used for the analyses of the relationship between encoding strategies and memory performance. (B) The model used for the analyses of the relationship between intelligence and memory performance. 
Sato \& Yoshikawa: J Gen Psychol

Table 1. Fit indices for the SEM models of the relationship between strategies and memory. The endorsed model is indicated in bold. $\mathrm{F}=$ feature; $\mathrm{C}=$ configuration; $\mathrm{S}=$ similarity; $\mathrm{P}=$ preference. $\mathrm{N}$ $=123$.

Face Short

\begin{tabular}{|c|c|c|c|c|c|c|c|c|c|c|}
\hline \multicolumn{2}{|c|}{ Model (Path) } & \multirow[b]{2}{*}{$\mathrm{df}$} & \multirow[b]{2}{*}{$\chi^{2}$} & \multirow[b]{2}{*}{ AGFI } & \multirow[b]{2}{*}{ RMSEA } & \multirow[b]{2}{*}{$\mathrm{AIC}$} & \multicolumn{4}{|c|}{ Standardized Path Coefficicents } \\
\hline Number & Content & & & & & & $\mathrm{F} \rightarrow$ & $\mathrm{C} \rightarrow$ & $\mathrm{A} \rightarrow$ & $\mathrm{P} \rightarrow$ \\
\hline 4 & All & - & - & - & - & 30.00 & 0.04 & 0.01 & 0.07 & -0.02 \\
\hline 3 & $\mathrm{~F} \rightarrow, \mathrm{C} \rightarrow, \mathrm{S} \rightarrow$ & 1 & 0.03 & 1.00 & 0.00 & 28.03 & 0.04 & 0.01 & 0.07 & \\
\hline 3 & $\mathrm{~F} \rightarrow, \mathrm{C} \rightarrow, \mathrm{P} \rightarrow$ & 1 & 0.62 & 0.97 & 0.00 & 28.62 & 0.03 & 0.01 & & -0.02 \\
\hline 3 & $\mathrm{~F} \rightarrow \mathrm{S} \rightarrow \mathrm{P} \rightarrow$ & 1 & 0.02 & 1.00 & 0.00 & 28.02 & 0.04 & & 0.07 & -0.02 \\
\hline 3 & $\mathrm{C} \rightarrow \mathrm{S} \rightarrow \mathrm{P} \rightarrow$ & 1 & 0.19 & 0.99 & 0.00 & 28.19 & & 0.02 & 0.07 & -0.02 \\
\hline 2 & $\mathrm{~F} \rightarrow, \mathrm{C} \rightarrow$ & 2 & 0.66 & 0.98 & 0.00 & 26.66 & 0.03 & 0.01 & & \\
\hline 2 & $\mathrm{~F} \rightarrow \mathrm{S} \rightarrow$ & 2 & 0.05 & 1.00 & 0.00 & 26.05 & 0.04 & & 0.07 & \\
\hline 2 & $\mathrm{~F} \rightarrow \mathrm{P} \rightarrow$ & 2 & 0.63 & 0.99 & 0.00 & 26.63 & 0.03 & & & -0.02 \\
\hline 2 & $\mathrm{c} \rightarrow \mathrm{S} \rightarrow$ & 2 & 0.24 & 0.99 & 0.00 & 26.24 & & 0.02 & 0.07 & \\
\hline 2 & $\mathrm{C} \rightarrow \mathrm{P} \rightarrow$ & 2 & 0.71 & 0.98 & 0.00 & 26.71 & & 0.01 & & -0.02 \\
\hline 2 & $\mathrm{P} \rightarrow \mathrm{S} \rightarrow$ & 2 & 0.22 & 1.00 & 0.00 & 26.22 & & & 0.06 & -0.02 \\
\hline 1 & $\mathrm{~F} \rightarrow$ & 3 & 0.67 & 0.99 & 0.00 & 24.67 & 0.03 & & & \\
\hline 1 & $\mathrm{C} \rightarrow$ & 3 & 0.76 & 0.99 & 0.00 & 24.76 & & 0.01 & & \\
\hline 1 & $\mathrm{~s} \rightarrow$ & 3 & 0.27 & 1.00 & 0.00 & 24.27 & & & 0.07 & \\
\hline 1 & $\mathrm{P} \rightarrow$ & 3 & 0.72 & 0.99 & 0.00 & 24.72 & & & & -0.02 \\
\hline 0 & None & 4 & 0.77 & 0.99 & 0.00 & 22.77 & & & & \\
\hline \multicolumn{7}{|c|}{ Face Long } & & & & \\
\hline \multicolumn{2}{|c|}{ Model (Path) } & & & & & & \multicolumn{4}{|c|}{ Standardized Path Coefficicents } \\
\hline Number & Content & $d f$ & $\chi^{2}$ & AGFI & RMSEA & $\mathrm{AIC}$ & $\mathrm{F} \rightarrow$ & $\mathrm{c} \rightarrow$ & $\mathrm{A} \rightarrow$ & $\mathrm{P} \rightarrow$ \\
\hline 4 & All & - & - & - & - & 30.00 & -0.03 & 0.04 & 0.08 & -0.05 \\
\hline 3 & $\mathrm{~F} \rightarrow, \mathrm{C} \rightarrow, \mathrm{S} \rightarrow$ & 1 & 0.29 & 0.99 & 0.00 & 28.29 & -0.03 & 0.04 & 0.08 & \\
\hline 3 & $\mathrm{~F} \rightarrow, \mathrm{C} \rightarrow, \mathrm{P} \rightarrow$ & 1 & 0.71 & 0.97 & 0.00 & 28.71 & -0.05 & 0.03 & & -0.05 \\
\hline 3 & $\mathrm{~F} \rightarrow \mathrm{S} \rightarrow \mathrm{P} \rightarrow$ & 1 & 0.19 & 0.99 & 0.00 & 28.19 & -0.03 & & 0.07 & -0.05 \\
\hline 3 & $\mathrm{C} \rightarrow \mathrm{S} \rightarrow \mathrm{P} \rightarrow$ & 1 & 0.12 & 0.99 & 0.00 & 28.12 & & 0.04 & 0.08 & -0.05 \\
\hline 2 & $\mathrm{~F} \rightarrow, \mathrm{C} \rightarrow$ & 2 & 1.01 & 0.98 & 0.00 & 27.01 & -0.04 & 0.03 & & \\
\hline 2 & $\mathrm{~F} \rightarrow \mathrm{S} \rightarrow$ & 2 & 0.46 & 0.99 & 0.00 & 26.46 & -0.03 & & 0.08 & \\
\hline 2 & $\mathrm{~F} \rightarrow, \mathrm{P} \rightarrow$ & 2 & 0.84 & 0.98 & 0.00 & 26.84 & -0.04 & & & -0.05 \\
\hline 2 & $\mathrm{C} \rightarrow \mathrm{S} \rightarrow$ & 2 & 0.39 & 0.99 & 0.00 & 26.39 & & 0.04 & 0.08 & \\
\hline 2 & $\mathrm{C} \rightarrow \mathrm{P} \rightarrow$ & 2 & 0.97 & 0.98 & 0.00 & 26.97 & & 0.03 & & -0.05 \\
\hline 2 & $\mathrm{P} \rightarrow, \mathrm{S} \rightarrow$ & 2 & 0.29 & 0.99 & 0.00 & 26.29 & & & 0.08 & -0.05 \\
\hline 1 & $\mathrm{~F} \rightarrow$ & 3 & 1.13 & 0.98 & 0.00 & 25.13 & -0.04 & & & \\
\hline 1 & $\mathrm{c} \rightarrow$ & 3 & 1.24 & 0.98 & 0.00 & 25.24 & & 0.03 & & \\
\hline 1 & $\mathrm{~s} \rightarrow$ & 3 & 0.54 & 0.99 & 0.00 & 24.54 & & & 0.08 & \\
\hline 1 & $\mathrm{P} \rightarrow$ & 3 & 1.07 & 0.98 & 0.00 & 25.07 & & & & -0.05 \\
\hline 0 & None & 4 & 1.33 & 0.98 & 0.00 & 23.33 & & & & \\
\hline
\end{tabular}


Sato \& Yoshikawa: J Gen Psychol

(continued)

Soene Short

\begin{tabular}{|c|c|c|c|c|c|c|c|c|c|c|}
\hline \multicolumn{2}{|c|}{ Model (Path) } & \multirow[b]{2}{*}{$\mathrm{df}$} & \multirow[b]{2}{*}{$\chi^{2}$} & \multirow[b]{2}{*}{ AGFI } & \multirow[b]{2}{*}{ RMSEA } & \multirow[b]{2}{*}{$\mathrm{AIC}$} & \multicolumn{4}{|c|}{ Standardized Path Coefficicents } \\
\hline Number & Content & & & & & & $\mathrm{F} \rightarrow$ & $\mathrm{C} \rightarrow$ & $\mathrm{A} \rightarrow$ & $\mathrm{P} \rightarrow$ \\
\hline 4 & All & - & - & - & - & 30.00 & 0.02 & 0.08 & 0.08 & -0.13 \\
\hline 3 & $\mathrm{~F} \rightarrow, \mathrm{C} \rightarrow, \mathrm{S} \rightarrow$ & 1 & 2.03 & 0.90 & 0.09 & 30.03 & 0.01 & 0.07 & 0.08 & \\
\hline 3 & $\mathrm{~F} \rightarrow, \mathrm{C} \rightarrow, \mathrm{P} \rightarrow$ & 1 & 0.77 & 0.96 & 0.00 & 28.77 & 0.02 & 0.06 & & -0.13 \\
\hline 3 & $\mathrm{~F} \rightarrow, \mathrm{S} \rightarrow, \mathrm{P} \rightarrow$ & 1 & 0.68 & 0.97 & 0.00 & 28.68 & 0.03 & & 0.06 & -0.13 \\
\hline 3 & $\mathrm{C} \rightarrow \mathrm{S} \rightarrow \mathrm{P} \rightarrow$ & 1 & 0.05 & 1.00 & 0.00 & 28.05 & & 0.08 & 0.08 & -0.13 \\
\hline 2 & $\mathrm{~F} \rightarrow, \mathrm{C} \rightarrow$ & 2 & 2.78 & 0.93 & 0.06 & 28.78 & 0.01 & 0.05 & & \\
\hline 2 & $\mathrm{~F} \rightarrow \mathrm{S} \rightarrow$ & 2 & 2.60 & 0.94 & 0.05 & 28.60 & 0.03 & & 0.06 & \\
\hline 2 & $\mathrm{~F} \rightarrow \mathrm{P} \rightarrow$ & 2 & 1.16 & 0.97 & 0.00 & 27.16 & 0.03 & & & -0.13 \\
\hline 2 & $\mathrm{c} \rightarrow \mathrm{S} \rightarrow$ & 2 & 2.05 & 0.95 & 0.01 & 28.05 & & 0.07 & 0.08 & \\
\hline 2 & $\mathrm{C} \rightarrow \mathrm{P} \rightarrow$ & 2 & 0.80 & 0.98 & 0.00 & 26.80 & & 0.06 & & -0.13 \\
\hline 2 & $\mathrm{P} \rightarrow \mathrm{S} \rightarrow$ & 2 & 0.82 & 0.98 & 0.00 & 26.82 & & & 0.06 & -0.12 \\
\hline 1 & $\mathrm{~F} \rightarrow$ & 3 & 309 & 0.95 & 0.02 & 27.09 & 0.02 & & & \\
\hline 1 & $\mathrm{C} \rightarrow$ & 3 & 2.79 & 0.96 & 0.00 & 26.79 & & 0.05 & & \\
\hline 1 & $\mathrm{~S} \rightarrow$ & 3 & 2.68 & 0.96 & 0.00 & 26.68 & & & 0.06 & \\
\hline 1 & $\mathrm{P} \rightarrow$ & 3 & 1.26 & 0.98 & 0.00 & 25.26 & & & & -0.12 \\
\hline 0 & None & 4 & 3.14 & 0.96 & 0.00 & 25.14 & & & & \\
\hline \multicolumn{7}{|c|}{ Scene Long } & & & & \\
\hline \multicolumn{2}{|c|}{ Model (Path) } & \multirow[b]{2}{*}{$\mathrm{df}$} & \multirow[b]{2}{*}{$x^{2}$} & \multirow[b]{2}{*}{ AGFI } & \multirow[b]{2}{*}{ RMSEA } & \multirow[b]{2}{*}{$\mathrm{AIC}$} & \multicolumn{4}{|c|}{ Standardized Path Coefficicents } \\
\hline Number & Content & & & & & & $\mathrm{F} \rightarrow$ & $\mathrm{C} \rightarrow$ & $\mathrm{A} \rightarrow$ & $\mathrm{P} \rightarrow$ \\
\hline 4 & All & - & - & - & - & 30.00 & 0.07 & 0.14 & -0.01 & -0.07 \\
\hline 3 & $\mathrm{~F} \rightarrow, \mathrm{C} \rightarrow \mathrm{S} \rightarrow$ & 1 & 0.62 & 0.97 & 0.00 & 28.62 & 0.07 & 0.14 & -0.01 & \\
\hline 3 & $\mathrm{~F} \rightarrow, \mathrm{C} \rightarrow \mathrm{P} \rightarrow$ & 1 & 0.02 & 1.00 & 0.00 & 28.02 & 0.07 & 0.14 & & -0.07 \\
\hline 3 & $\mathrm{~F} \rightarrow, \mathrm{S} \rightarrow, \mathrm{P} \rightarrow$ & 1 & 2.17 & 0.90 & 0.10 & 30.17 & 0.10 & & -0.05 & -0.06 \\
\hline 3 & $\mathrm{C} \rightarrow, \mathrm{S} \rightarrow, \mathrm{P} \rightarrow$ & 1 & 0.61 & 0.97 & 0.00 & 28.61 & & 0.15 & -0.02 & -0.07 \\
\hline 2 & $\mathrm{~F} \rightarrow \mathrm{C} \rightarrow$ & 2 & 0.64 & 0.98 & 0.00 & 26.64 & 0.07 & 0.14 & & \\
\hline 2 & $\mathrm{~F} \rightarrow \mathrm{S} \rightarrow$ & 2 & 2.68 & 0.94 & 0.05 & 28.68 & 0.09 & & -0.04 & \\
\hline 2 & $\mathrm{~F} \rightarrow, \mathrm{P} \rightarrow$ & 2 & 2.41 & 0.94 & 0.04 & 28.41 & 0.10 & & & -0.06 \\
\hline 2 & $\mathrm{C} \rightarrow \mathrm{S} \rightarrow$ & 2 & 1.16 & 0.97 & 0.00 & 27.16 & & 0.15 & -0.02 & \\
\hline 2 & $\mathrm{C} \rightarrow \mathrm{P} \rightarrow$ & 2 & 0.63 & 0.98 & 0.00 & 26.63 & & 0.16 & & -0.07 \\
\hline 2 & $\mathrm{P} \rightarrow, \mathrm{S} \rightarrow$ & 2 & 3.31 & 0.92 & 0.07 & 29.31 & & & -0.05 & -0.06 \\
\hline 1 & $\mathrm{~F} \rightarrow$ & 3 & 2.92 & 0.95 & 0.00 & 26.92 & 0.10 & & & \\
\hline 1 & $\mathrm{c} \rightarrow$ & 3 & 1.19 & 0.98 & 0.00 & 25.19 & & 0.15 & & \\
\hline 1 & $\mathrm{~S} \rightarrow$ & 3 & 3.73 & 0.94 & 0.05 & 27.73 & & & -0.05 & \\
\hline 1 & $\mathrm{P} \rightarrow$ & 3 & 3.65 & 0.94 & 0.04 & 27.65 & & & & -0.06 \\
\hline 0 & None & 4 & 4.06 & 0.95 & 0.01 & 26.06 & & & & \\
\hline
\end{tabular}


Sato \& Yoshikawa: J Gen Psychol

Table 2. Fit indices for the SEM models of the relationship between intelligence and memory. The endorsed model is indicated in bold. $\mathrm{Vi}=$ visuospatial intelligence; $\mathrm{Ve}=$ verbal intelligence. $\mathrm{N}=$ 123.

Face Short

\begin{tabular}{|c|c|c|c|c|c|c|c|c|}
\hline \multicolumn{2}{|c|}{ Model (Path) } & \multirow[b]{2}{*}{$\mathrm{df}$} & \multirow[b]{2}{*}{$\chi^{2}$} & \multirow[b]{2}{*}{$\mathrm{AGFI}$} & \multirow[b]{2}{*}{ RMSEA } & \multicolumn{3}{|c|}{ Standardized Path Coefficic } \\
\hline Number & Content & & & & & $\mathrm{AIC}$ & $V i \rightarrow$ & $\mathrm{Ve}_{\mathrm{e}} \rightarrow$ \\
\hline 2 & Both & 12 & 6.26 & 0.97 & 0.00 & 38.26 & -0.25 & 0.36 \\
\hline 1 & $\mathrm{Vi} \rightarrow$ & 13 & 9.85 & 0.95 & 0.00 & 38.85 & 0.06 & \\
\hline 1 & $\mathrm{Ve} \rightarrow$ & 13 & 7.95 & 0.96 & 0.00 & 37.95 & & 0.16 \\
\hline 0 & none & 14 & 10.13 & 0.96 & 0.00 & 38.13 & & \\
\hline
\end{tabular}

Face Long

\begin{tabular}{|c|c|c|c|c|c|c|c|c|}
\hline \multicolumn{2}{|c|}{ Model (Path) } & \multirow[b]{2}{*}{$d f$} & \multirow[b]{2}{*}{$\chi^{2}$} & \multirow[b]{2}{*}{ AGFI } & \multirow[b]{2}{*}{ RMSEA } & \multicolumn{3}{|c|}{ Standardized Path Coeffi } \\
\hline Number & Content & & & & & AIC & $\mathrm{Vi} \rightarrow$ & $\mathrm{Ve} \rightarrow$ \\
\hline 2 & Both & 12 & 11.50 & 0.94 & 0.00 & 43.51 & 0.25 & -0.44 \\
\hline 1 & $V i \rightarrow$ & 13 & 16.53 & 0.93 & 0.05 & 46.35 & -0.12 & \\
\hline 1 & $\mathrm{Ve} \rightarrow$ & 13 & 13.12 & 0.94 & 0.01 & 43.12 & & -0.23 \\
\hline 0 & none & 14 & 17.64 & 0.93 & 0.05 & 45.64 & & \\
\hline
\end{tabular}

Scene Short

\begin{tabular}{|c|c|c|c|c|c|c|c|c|}
\hline \multicolumn{2}{|c|}{ Model (Path) } & \multirow[b]{2}{*}{$d f$} & \multirow[b]{2}{*}{$\chi^{2}$} & \multirow[b]{2}{*}{$\mathrm{AGFI}$} & \multirow[b]{2}{*}{ RMSEA } & \multicolumn{3}{|c|}{ Standardized Path Coefficic } \\
\hline Number & Content & & & & & $\mathrm{AIC}$ & $V_{i \rightarrow}$ & $V_{e} \rightarrow$ \\
\hline 2 & Both & 12 & 7.16 & 0.96 & 0.00 & 39.16 & 0.25 & -0.05 \\
\hline 1 & $v i \rightarrow$ & 13 & 7.23 & 0.97 & 0.00 & 37.23 & 0.21 & \\
\hline 1 & $V e \rightarrow$ & 13 & 8.95 & 0.96 & 0.00 & 38.95 & & 0.16 \\
\hline 0 & none & 14 & 11.35 & 0.95 & 0.00 & 39.35 & & \\
\hline \multicolumn{9}{|c|}{ Scene Long } \\
\hline \multicolumn{2}{|c|}{ Model (Path) } & & & & & \multicolumn{3}{|c|}{ Standardized Path Coefficio } \\
\hline Number & Content & $d f$ & $\chi^{2}$ & $\mathrm{AGFI}$ & RMSEA & $\mathrm{AIC}$ & $v_{i \rightarrow}$ & $\mathrm{Ve}_{\mathrm{e}} \rightarrow$ \\
\hline 2 & Both & 12 & 13.95 & 0.94 & 0.04 & 45.95 & 0.07 & 0.16 \\
\hline 1 & $V i \rightarrow$ & 13 & 14.53 & 0.94 & 0.03 & 44.53 & 0.21 & \\
\hline 1 & $\mathrm{Ve} \rightarrow$ & 13 & 14.07 & 0.94 & 0.03 & 44.07 & & 0.22 \\
\hline 0 & none & 14 & 18.32 & 0.93 & 0.05 & 46.32 & & \\
\hline
\end{tabular}


optimal. For scene recognition memory at a short-interval, the model in which visuospatial intelligence had a positive influence on memory was optimal. For scene recognition memory at a long-interval, the model in which verbal intelligence had a positive influence on memory was optimal. The fit of all these models was sufficiently high.

\section{Discussion}

Our results showed that recognition memory performance was better for faces than for scenes at both short (20 minutes) and long ( 3 weeks) retention intervals. This result indicates that memory for faces is more robust than is that for scenes regardless of retention interval. Additionally, our results showed that performance for faces and scenes showed different patterns across retention intervals. The relationship between encoding strategies and memory performance and that between intelligence and memory performance differed for faces and scenes. These results suggest that memory for faces and scenes relies on different cognitive mechanisms. Taken together, these results provide empirical support for the claim that memory for faces is robust and unique.

Our results showed that the patterns of recognition memory for faces and scenes were qualitatively different across retention intervals of 20 minutes and 3 weeks. The results are consistent with a previous study reporting that facial recognition memory differed qualitatively at retention intervals of 10 minutes and 1 week (Yoshikawa, 1995). The results are also in line with previous neuropsychological data indicating that recognition memory for faces under different retention intervals involved dissociable neural substrates (Bengner et al., 2006; Hotting et al., 2010). Although most previous research investigated recognition memory with only a single retention interval, the present data suggest a need for investigating the effect of different retention intervals on long-term memory.

Our results did not show clear effects of encoding strategies on face recognition memory. This result is consistent with a number of previous studies that investigated effects of intentional cognitive strategies on facial memory (e.g., Woodhead et al., 1979). Although some other studies reported the effects of encoding strategies on face recognition memory (e.g., Bower \& Karlin, 1974), differences in experimental procedures may account for this inconsistency. Whereas the previous research reporting no strategy effect used intentional memory tasks (e.g., Woodhead et al., 1979), as in the present study, the research that reported an effect used incidental memory tasks (e.g., Bower \& Karlin, 1974). Hence, the strategies may be helpful only during incidental encoding. It is possible that the ability to memorize faces is sufficiently supported by normal effort, with no room for significant improvement (cf. Malpass, 1981).

Our results showed that verbal intelligence had a negative influence on facial memory. In line with this result, several previous studies have found that verbal descriptions can impair the subsequent recognition of faces (verbal overshadowing effect; e.g., Schooler \& Engstler-Schooler, 
1990; Kitagami, Sato, \& Yoshikawa, 2002). Together with these data, we speculate that the negative influence of verbal intelligence on face memory may be mediated by verbal processing during retention intervals.

Our results provide some suggestions for applied research. For example, the role of facial memory in eyewitness testimony has been investigated extensively (Loftus \& Doyle, 1997). In the context of eyewitness testimony, large individual differences in memory performance were found (e.g., Ward \& Loftus, 1985), suggesting the importance of investigating the factors that contribute to these differences. Specifically, the negative influence of verbal intelligence in this study was found at long retention intervals and hence could be relevant for eyewitness testimony. In future research, factors such as intelligence may require attention in investigating eyewitness memory.

Promising directions for further investigation include identifying the hardware for face recognition memory. The neural substrates involved in the recognition of unfamiliar faces remain untested and unclear compared with those involved in the recognition of familiar faces (for a review, see Johnston and Edmonds, 2009). For example, one neuroimaging study measured brain activity during memory tasks for unfamiliar and familiar faces and reported that recognition of unfamiliar compared with familiar faces showed brain activity over a smaller area, which was hard to interpret (Leveroni et al., 2000). To date, no neuroimaging study has compared recognition memory for unfamiliar faces and control stimuli such as unfamiliar scenes. Recently, one neuropsychological study conducted the first systematic comparison of recognition memory for unfamiliar faces and scenes (Taylor et al., 2007). The study tested patients with medial temporal damage under the short-term retrieval condition from the present study and showed that selective damage to the hippocampus, known to be involved in recognition memory (cf. Squire, Stark, \& Clark, 2004), impaired memory for scenes but not for faces. The data appear consistent with the idea of the robustness of facial recognition memory. Additionally, neuropsychological studies have shown that recognition memory for faces is related to different neural systems across different retention intervals, specifically the frontal-parietal lobes for short-term and the medial temporal lobes for long-term retention intervals (Bengner et al., 2006; Hotting et al., 2010). Based on these findings together with the current data, we speculate that comparing the neural activities related to recognition memory for faces and scenes at different retention intervals and measuring relevant cognitive variables would make an interesting contribution to future neuroscientific research on facial memory.

Some limitations to this study should be acknowledged. First, we simply compared the memory performance for faces with that for control stimuli, as in several previous studies (e.g., Yin, 1970; Taylor et al., 2007). This approach was used because we simultaneously examined several other variables. We believe that our results suggest the uniqueness of face memory, especially in the context of ample evidence in the extant literature indicating the special character of facial processing 
compared with that of processing other objects (for a review, see Robbins \& McKone, 2007). However, the results of this type of comparison can also be interpreted to suggest that the memory processing for scenes is unique compared with that for non-scenic stimuli, including faces. Consistent with such reasoning, some neuroscientific studies have shown that distinctive brain regions were involved in the mnemonic processing of scenes and objects (e.g., Awipi \& Davachi, 2008). Further research using multiple categories of stimuli would be necessary to investigate the memory mechanisms for faces and other stimulus categories.

Second, we investigated the influence of encoding strategies on memory performance by asking participants to rate their use of strategies. This self-report method may be subject to several biases, such as failures of self-evaluation (cf. Paulhus \& Vazire, 2007). Additionally, unlike experimental manipulations (cf. Eyesenk, 2000), our correlational method cannot provide clear evidence for causal relationships. As some previous findings have suggested parallel patterns for subjective ratings and objective manipulations of encoding strategies (e.g., Bouazzaoui et al., 2010), future studies involving manipulation of memory strategies would strengthen our findings about the mechanisms of recognition memory for faces and scenes.

\section{References}

Awipi, T., \& Davachi, L. (2008). Content-specific source encoding in the human medial temporal lobe. Journal of Experimental Psychology: Learning, Memory, and Cognition, 34, 769-779.

Bengner, T., Malina, T., Lindenau, M., Voges, B., Goebell, E., \& Stodieck, S. (2006). Face memory in MRI-positive and MRI-negative temporal lobe epilepsy. Epilepsia, 47, 1904-1914.

Bouazzaoui, B., Isingrini, M., Fay, S., Angel, L., Vanneste, S., Clarys, D., \& Taconnat, L. (2010). Aging and self-reported internal and external memory strategy uses: The role of executive functioning. Acta Psychologica, 135, 59-66.

Bower, G. H., \& Karlin, M. B. (1974). Depth of processing pictures of faces and recognition memory. Journal of Experimental Psychology, 103, 751-757.

Bowles, D. C., McKone, E., Dawel, A., Duchaine, B., Palermo, R., Schmalzl, L., Rivolta, D., Wilson, C. E., and Yovel, G. (2009). Diagnosing prosopagnosia: Effects of ageing, sex, and participant-stimulus ethnic match on the Cambridge Face Memory Test and Cambridge Face Perception Test. Cognitive Neuropsychology, 26, 423-455.

Coin, C., \& Tiberghien, G. (1997). Encoding activity and face recognition. Memory, 5, 545-568.

Coyle, T. R. (2001). IQ is related to the worst performance rule in a memory task involving children. Intelligence, 29, 117-129.

Craik, F. I. M., \& Lockhart, R. S. (1972). Levels of processing: A framework for memory research. Journal of Verbal Learning and Verbal Behavior, 11, 671-684.

Diamond, R., \& Carey, S. (1986). Why faces are and are not special: An effect of expertise. Journal 
Sato \& Yoshikawa: J Gen Psychol

of Experimental Psychology: General, 115, 107-117.

Diesfeldt, H., \& Vink, M. (1989). Recognition memory for words and faces in the very old. British Journal of Clinical Psychology, 28, 247-253.

Dobson, E., \& Rust, J. O. (1994). Memory for objects and faces by the mentally retarded and nonretarded. Journal of Psychology, 128, 315-322.

Elgar, K., \& Campbell, R. (2001). Annotation: The cognitive neuroscience of face recognition: Implications for developmental disorders. Journal of Child Psychology and Psychiatry, 42, $705-717$.

Eysenck, M. W. (2000). Psychology: A student's handbook. Hove, UK: Psychology Press.

Feinman, S., \& Entwisle, D. R. (1976). Children's ability to recognize other children's faces. Child Development, 47, 506-510.

Gauthier, I., Skudlarski, P., Gore, J. C., \& Anderson, A W. (2000). Expertise for cars and birds recruits brain areas involved in face recognition. Nature Neuroscience, 3, 191-197.

Gauthier, I., Williams, P., Tarr, M. J., \& Tanaka, J. (1998). Training 'greeble' experts: A framework for studying expert object recognition processes. Vision Research, 38, 2401-2428.

Grill-Spector, K., Knouf, N., \& Kanwisher, N. (2004). The fusiform face area subserves face perception, not generic within-category identification. Nature Neuroscience, 7, 555-562.

Herlitz, A., \& Yonker, J. E. (2002). Sex differences in episodic memory: The influence of intelligence. Journal of Clinical and Experimental Neuropsychology, 24, 107-114.

Hötting, K., Katz-Biletzky, T., Malina, T., Lindenau, M., \& Bengner, T. (2010). Long-term versus short-term memory deficits for faces in temporal lobe and generalized epilepsy patients. Journal of the International Neuropsychological Society, 16, 574-578.

Howells, T. H. (1938). A study of ability to recognize faces. Journal of Abnormal and Social Psychology, 33, 124-127.

Johnston, R. A., \& Edmonds, A. J. (2009). Familiar and unfamiliar face recognition: A review. Memory, 17, 577-596.

Kaess, W. A., \& Witryol, S. L. (1955). Memory for names and faces: A characteristic of social intelligence? Journal of Applied Psychology, 39, 457-462.

Kitagami, S., Sato, W., \& Yoshikawa, S. (2002). The influence of test-set similarity in verbal overshadowing. Applied Cognitive Psychology, 16, 963-972.

Leveroni, C. L., Seidenberg, M., Mayer, A. R., Mead, L. A., Binder, J. R., \& Rao, S. M. (2000). Neural systems underlying the recognition of familiar and newly learned faces. Journal of Neuroscience, 20, 878-886.

Loftus, E. F. , \& Doyle, J. M. (1997). Eyewitness testimony: Civil and criminal (3rd ed.). Charlottesville, VA: Lexis Law Pub.

McCartney, J. R. (1987). Mentally retarded and nonretarded subjects' long-term recognition memory. 
American Journal of Mental Retardation, 92, 312-317.

Malpass, R. S. (1981). Training in face recognition. In G. Davies, H. Ellis, \& J. Shepherd (Eds.), Perceiving and remembering faces (pp. 271-285). London: Academic Press.

McNeil, J. E., \& Warrington, E. K. (1993). Prosopagnosia: A face-specific disorder. Quarterly Journal of Experimental Psychology: Human Experimental Psychology, 46, 1-10.

Nakamura, K., Kawashima, R., Sato, N., Nakamura, A., Sugiura, M., Kato, T., Hatano, K., Ito, K., Fukuda, H., Schormann, T., \& Zilles, K. (2000). Functional delineation of the human occipito-temporal areas related to face and scene processing: A PET study. Brain, 123, 1903-1912.

Osaka, A., \& Umemoto, A. (1973). Shintei Kyodai NX 15 dai nihan [Kyoto University new NX 15 intelligence test]. Tokyo: Taisei Shuppan.

Parkin, A. J., \& Goodwin, E. (1983). The influence of different processing strategies on the recognition of transformed and untransformed faces. Canadian Journal of Psychology, 37, 272-277.

Paulhus, D. L., \& Vazire, S. (2007). The self-report method. In R. W. Robins, R. C. Fraley, \& R. F. Krueger (Eds.), Handbook of research methods in personality psychology (pp. 224-239). New York: Guilford.

Robbins, R. McKone, E. (2007). No face-like processing for objects-of-expertise in three behavioural tasks. Cognition, 103, 34-79.

Sato, T., Namiki, H., Ando, J., \& Hatano, G. (2004). Japanese conception of and research on human intelligence. In R. J. Sternberg (Ed.), International handbook of intelligence (pp. 302-324). Cambridge, UK: Cambridge University Press.

Schooler, J. W., \& Engstler-Schooler, T. Y. (1990). Verbal overshadowing of visual memories: Some things are better left unsaid. Cognitive Psychology, 22, 36-71.

Squire, L. R., Stark, C. E., \& Clark, R. E. (2004). The medial temporal lobe. Annual Review of Neuroscience, 27, 279-306.

Taylor, K. J., Henson, R. N., \& Graham, K. S. (2007). Recognition memory for faces and scenes in amnesia: Dissociable roles of medial temporal lobe structures. Neuropsychologia, 45, $2428-2438$.

Wagenaar, W. A., \& van der Schrier, J. H. (1996). Face recognition as a function of distance and illumination: A practical tool for use in the courtroom. Psychology, Crime \& Law, 2, 321-332.

Ward, R. A., \& Loftus, E. F. (1985). Eyewitness performance in different psychological types. Journal of General Psychology, 112, 191-200.

Wojcikiewicz, J. (1990). Decoding of memory traces as a function of witness' intelligence. Forensic Science International, 46, 83-85.

Woodhead, M. M., Baddeley, A. D., \& Simmonds, D. C. V. (1979). On training people to recognize 
Sato \& Yoshikawa: J Gen Psychol

faces. Ergonomics, 22, 333-343.

Yin, R. K. (1969). Looking at upside-down faces. Journal of Experimenal Psychology, 81, 141-145.

Yin, R. K. (1970). Face recognition by brain-injured patients: A dissociable ability? Neuropsychologia, 8, 395-402.

Yoshikawa, S. (1995). A relationship between everyday cognition and recognition memory for unfamiliar faces. Poster presented at 59th Annual Convention of Japanase Psychological Association, Nishihara, Japan. 